\title{
Radix ranunculus temate saponins sensitizes ovarian cancer to Taxol via upregulation of miR-let-7b
}

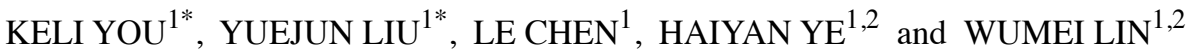 \\ ${ }^{1}$ Department of Gynecology, Guangdong Provincial People's Hospital, Guangdong Academy of \\ Medical Sciences, Guangzhou, Guangdong 510080; ${ }^{2}$ The Second School of Clinical Medicine, \\ Southern Medical University, Guangzhou, Guangdong 510280, P.R. China
}

Received November 5, 2020; Accepted December 7, 2021

DOI: $10.3892 /$ etm.2022.11244

\begin{abstract}
A common cause of treatment failure in ovarian cancer is acquired drug resistance. Therefore, effective novel drugs against chemoresistance need to be developed. MicroRNAs (miRNAs or miRs) serve key regulatory roles in tumorigenesis and chemoresistance. The objective of the present study was to explore the role of miR-let-7b in ovarian cancer chemoresistance, and to develop novel strategy for the treatment of drug-resistant ovarian cancer. For this purpose, reverse transcription-quantitative $\mathrm{PCR}$ was performed to evaluate the expression level of miR-let-7b in fresh ovarian cancer tissues and cell lines. miR-let-7b mimic was transfected into ovarian cancer cell lines. Functional experiments, cell apoptosis and cell viability assays were carried out to identify the tumor-suppressor function of miR-let-7b. The treatment effect of Radix ranunculus temate saponins (RRTS), one of the primary constituents extracted from the traditional Chinese medicine radix Ranunculi ternati, was identified in vitro and in vivo. The results revealed that miR-let-7b was downregulated significantly in chemoresistant ovarian cancer patients. miR-let-7b overexpression suppressed cell growth and invasion and enhanced sensitivity to Taxol of ovarian cancer cells. Furthermore, miR-let-7b levels in ovarian cancer tissue were inversely associated with collagen type III $\alpha 1$ chain (COL3A1) levels. COL3A1, a non-fibrillar collagen associated with chemoresistance, was targeted by miR-let-7b. RRTS showed cytotoxic effects on ovarian cancer cells through inducing miR-let-7b expression and decreasing COL3A1 expression.
\end{abstract}

Correspondence to: Professor Wumei Lin or Professor Haiyan Ye, Department of Gynecology, Guangdong Provincial People's Hospital, Guangdong Academy of Medical Sciences, 106 Zhongshan Second Road, Guangzhou, Guangdong 510080, P.R. China

E-mail: 461099006@qq.com

E-mail: yanzi8174296@163.com

${ }^{*}$ Contributed equally

Key words: microRNA-let7b, collagen type III $\alpha 1$ chain, Taxol-resistant, ovarian cancer, radix ranunculus temate saponins
In addition, RRTS sensitized ovarian cancer to Taxol both in vitro and in vivo. In conclusion, the present results revealed synergistic cytotoxicity of RRTS and Taxol on against ovarian cancer cells via upregulating expression of miR-let-7b. Combination of Taxol and RRTS may be a novel treatment strategy for patients with TR ovarian cancer.

\section{Introduction}

Ovarian cancer is the most lethal gynecological malignancy; $>70 \%$ patients diagnosed with stage III and IV cancer show poor survival rate due to treatment failure, worldwide $(1,2)$. Cytoreductive surgery is the main surgical method for patients with advanced stage ovarian cancer, followed by combined chemotherapy with paclitaxel and platinum, and is considered to be the standard treatment for ovarian cancer (2-4). However, one common cause for treatment failure is acquired drug resistance due to post-surgery chemotherapy (5-7). Therefore, it is crucial to identify the mechanism of acquired drug resistance in patients with advanced ovarian cancer and to develop novel targets for the treatment of drug-resistant ovarian cancer.

MicroRNAs (miRNAs or miRs) are small non-coding RNAs that negatively regulate target genes at the posttranscriptional level (8). Numerous studies have demonstrated the regulatory role of miRNAs in multiple biological processes, including tumorigenesis (9-11). Specific miRNA expression patterns are involved in tumor progression, which includes processes such as cell proliferation, differentiation, migration, immune suppression and drug resistance $(12,13)$. miR-let-7b belongs to the let-7 family and functions as a tumor suppressor gene (14-16). Previous studies have reported significant downregulation of miR-let-7b in several types of cancer, such as multiple myeloma, glioma and osteosarcoma (16-18). However, the impact of miR-let-7b on carcinogenesis of ovarian cancer remains unclear.

In traditional Chinese medicine, radix Ranunculus ternati is applied in the treatment of numerous types of disease, including scrofula, tuberculosis and pharyngitis (19), and comprises saponins, polysaccharides and certain fatty substances (20,21). Radix ranunculus temate saponins (RRTS) has shown satisfactory in vitro ability to suppress gastric cancer cells growth and proliferation $(22,23)$. However, its underlying molecular mechanisms need to be elucidated. 
In the present study, the roles of miR-let-7b in ovarian cancer were investigated. We further explored the effect of RRTS on ovarian cancer and discovered its role suppressing ovarian cancer cells.

\section{Materials and methods}

Patient samples and clinical data. A total of 57 females (age, 32-75 years; stage I to IV) were enrolled and pathologically diagnosed with high-grade serous ovarian cancer at Sun Yat-sen University Cancer Center (SYSUCC) in Guangzhou, Guangdong, China, from October 2008 to May 2016. Written informed consent was provided by all patients. The present study was approved by the Research and Ethical Committee of Guangdong Provincial People's Hospital and complied with all relevant ethical regulations. All specimens were confirmed as primary ovarian cancer by pathological examination. None of the patients had received chemotherapy before the surgery. Fresh samples were collected $<30$ min following surgical removal during routine surgery and stored at $-80^{\circ} \mathrm{C}$ in the cancer resource bank of SYSUCC. Total RNA was extracted using TRIzol ${ }^{\circledR}$ (Invitrogen; Thermo Fisher Scientific, Inc.).

To compare the expression of miR-let-7b in tumor and normal tissues, fresh high-grade ovarian serous cancer and matched normal fallopian tube tissue were collected from six female patients (age, 39-67 years, stage I and II) who received comprehensive surgical staging (which is the main surgical method for patients with early-stage ovarian cancer), or cytoreductive surgery at SYSUCC, between November 2010 to August 2015. Matched normal fallopian tissues were used as healthy tissues.

In addition, fresh high-grade ovarian serous cancer tissue samples were collected from 12 female patients (age, 44-71 years, stage III and IV) who received cytoreductive surgery and subsequent chemotherapy at SYSUCC, between October 2008 and April 2011 to identify the expression levels of miR-let-7b in chemo-sensitive and -resistant ovarian cancer. Patients with recurrent tumor $<6$ months following chemotherapy were considered TR.

High-grade ovarian serous cancer tissue samples were collected from 39 female patients (age, 32-75 years, stage III and IV) who received comprehensive staging or cytoreductive surgery at SYSUCC, between October 2008 and May 2016, to investigate the association between miR-let-7b and COL3A1 in ovarian cancer.

Cell lines and culture. Ovarian cancer cell lines (A2780, A2780/TR, OVCAR3, SK-OV-3 and SK-OV-3/TR) were acquired from American Type Culture Collection. A2780, A2780/TR and OVCAR3 cells were cultured in Dulbecco's modified Eagle's medium (DMEM; Gibco; Thermo Fisher Scientific, Inc.) containing 10\% fetal bovine serum (FBS; Gibco; Thermo Fisher Scientific, Inc.) in an incubator at $37^{\circ} \mathrm{C}$ with $5 \% \mathrm{CO}_{2}$. SK-OV-3 and SK-OV-3/TR cells were cultured in Roswell Park Memorial Institute (RPMI)-1640 (Gibco; Thermo Fisher Scientific, Inc.) containing 10\% FBS in an incubator at $37^{\circ} \mathrm{C}$ with $5 \% \mathrm{CO}_{2}$.

Transient miRNA transfection. miRNA-let-7b mimic (5'-UGAGGUAGUAGGUUGUGUGGUU-3') and negative control (5'-UUUGUACUACACAAAAGUACUG-3') were synthesized by Ribobio. A2780, OVCAR3 and SK-OV-3 cells $\left(1 \times 10^{5}\right.$ cells/well) were divided into groups, namely the control group (Mock), the negative control (NC) group and the miR-let-7b group. Cells in the miR-let-7b group were transfected with miRNA-let-7b mimic (50 $\mathrm{nM})$ using Lipofectamine ${ }^{\circledR} 3000$ (Invitrogen; Thermo Fisher Scientific, Inc.), according to the manufacturer's protocol. Cells in the NC group were transfected with negative control. The control group was left untreated. After $48 \mathrm{~h}$ transfection, cells were used for subsequent experimentation.

Reverse transcription-quantitative (RT-q) PCR. Total RNA was extracted from tissues or cells (A2780, OVCAR3 and SK-OV-3) using TRIzol ${ }^{\circledR}$ (Thermo Fisher Scientific, Inc.) according to the manufacturer's instruction, followed by determination of the RNA concentration. PrimeScript RT reagent kit (Takara Biotechnology Co., Ltd.) was used to synthesize the complementary DNA. Mature miRNAs in the sample were reverse-transcribed to cDNA using TaqMan Advanced miRNA cDNA Synthesis kit (Thermo Fisher Scientific, Inc.). RT-qPCR was performed using SYBR Green (Takara Biotechnology Co., Ltd.). GAPDH and U6 were used to normalize mRNA and miRNA levels, respectively. The PCR process was: Initial denaturing $10 \mathrm{~min}$ at $95^{\circ} \mathrm{C}$; denaturation $10 \mathrm{sec}$ at $95^{\circ} \mathrm{C}$; annealing $20 \mathrm{sec}$ at $60^{\circ} \mathrm{C}$; and extension $15 \mathrm{sec}$ at $72^{\circ} \mathrm{C}$; for 40 cycles. The relative expression levels of genes were calculated using the $2^{-\Delta \Delta \mathrm{Cq}}$ method (24). All assays were performed in triplicate. Each test was repeated three times. The primer sequences were as follows: miR-let-7b forward, 5'-GGGTGA GGTAGTAGGTTGTGTG-3' and reverse, 5'-CAGGGAAGG CAGTAGGTTGT-3'; U6 forward, 5'-CTCGCTTCGGCAGCA CA-3' and reverse, 5'-AACGCTTCACGAATTTGCGT-3'; COL3A1 forward, 5'-GCCAAATATGTGTCTGTGACT CA-3' and reverse, 5'-GGGCGAGTAGGAGCAGTTG-3' and GAPDH forward, 5'-GTCTCCTCTGACTTCAACAGCG-3' and reverse, 5'-ACCACCCTGTTGCTGTAGCCAA-3'.

Cell Counting Kit (CCK)-8 assay. CCK-8 assay was used to detect the viability of cells.

To identify the role of miR-let-7b in ovarian cancer cells, A2780 cells overexpressing miR-let-7b or control miRNA were seeded into a 96-well culture plate at a density of $1 \times 10^{4}$ cells/well and grown in DMEM supplemented with $10 \% \mathrm{FBS}$ at $37^{\circ} \mathrm{C}$. The cells were treated with Taxol $(0.00$, $6.25,12.50,25.00,50.00,100.00 \mathrm{nM})$ for $16 \mathrm{~h}$, then were detected by CCK-8 assay.

To investigate the treatment effect of RRTS, A2780 and SK-OV-3 cells were seeded into a 96-well culture plate at a density of $1 \times 10^{4}$ cells/well and grown in DMEM or RMPI-1640 supplemented with $10 \% \mathrm{FBS}$ at $37^{\circ} \mathrm{C}$. These cells were treated with RRTS $(0.00,6.25,12.50,25.00,50.00,100.00$, $200.00 \mu \mathrm{g} / \mathrm{ml}$ ) for $48 \mathrm{~h}$, then were detected by CCK- 8 assay.

To investigate whether RRTS sensitizes ovarian cancer cells to Taxol, A2780, A2780/TR, SK-OV-3 and SK-OV-3/TR cells were seeded into a 96-well culture plate at a density of $1 \times 10^{4}$ cells/well and grown in DMEM or RMPI-1640 supplemented with $10 \% \mathrm{FBS}$ at $37^{\circ} \mathrm{C}$. These cells were pre-treated with $25 \mu \mathrm{g} / \mathrm{ml}$ RRTS for $24 \mathrm{~h}$, followed by Taxol $(0.000,3.125$, $6.250,12.500,25.000,50.000$ and $100.000 \mathrm{nM})$ for a further $24 \mathrm{~h}$, then were detected by CCK- 8 assay. 
For CCK-8 assay, $20 \mu 1$ CCK-8 reagent (Shanghai Yeasen Biotechnology Co., Ltd.) was added to each well. The plate was incubated for $2 \mathrm{~h}$, followed by measurement of the optical density at $450 \mathrm{~nm}$.

MTT assay. MTT assay was used to detect the metabolic activity of cells. A2780, OVCAR3 and SK-OV-3 cells overexpressing miR-let-7b or control miRNA were seeded into a 96-well culture plate at a density of 500 cells/well and grown in DMEM or RMPI-1640 supplemented with 10\% FBS. MTT reagent (Sigma-Aldrich; Merck $\mathrm{KGaA}$ ) was dissolved in PBS $(5 \mathrm{mg} / \mathrm{ml})$. Medium was replaced with fresh DMEM or RMPI-1640 + 10\% FBS + 10\% MTT and incubated for $4 \mathrm{~h}$ at $37^{\circ} \mathrm{C}$. After removing the incubation medium, formazan crystals were dissolved in $200 \mu \mathrm{l}$ DMSO. Optical density was measured at $570 \mathrm{~nm}$.

Wound healing assay. Wound healing assay was used to detect cell migration ability. A2780, OVCAR3 and SK-OV-3 cells overexpressing miR-let-7b or control miRNA were seeded into 6-well culture plates and grown in DMEM or RMPI-1640 supplemented with 10\% FBS until 90\% confluence. Confluent cells were scratched with a pipette tip. Culture medium was removed and cells were rinsed with PBS, then incubated in DMEM or RMPI-1640 without FBS. Images were captured using a Nikon Coolpix camera at 0 and $24 \mathrm{~h}$. The scratch area (SA) was measured using Image-Pro Plus 6.0 (NIH) and wound healing rate was calculated as follows: Wound healing rate $=$ (initial SA-final SA)/initial SA.

Matrigel invasion assay. Cell invasion was determined using Matrigel-coated Transwell cell culture chambers (Corning, Inc.). Matrigel (BD Biosciences) was thawed on ice overnight and diluted in serum free-cold DMEM or RMPI-1640 $(2 \mathrm{mg} / \mathrm{ml})$. Diluted Matrigel $(100 \mu \mathrm{l})$ was placed into upper chamber of 24-well Transwell and incubated at $37^{\circ} \mathrm{C}$ for $4 \mathrm{~h}$ for gelling. A2780, OVCAR3 and SK-OV-3 cells overexpressing miR-let-7b or control miRNA were serum starved for $12 \mathrm{~h}$ at $37^{\circ} \mathrm{C}$, then trypsinized, resuspended in serum-free DMEM or RMPI-1640. Cells $\left(1 \times 10^{5}\right)$ were seeded in the upper chamber of the Transwell insert coated with Matrigel. The lower chamber was filled with DMEM or RMPI-1640 containing 10\% FBS as a chemoattractant. Following incubation for $24 \mathrm{~h}$ at $37^{\circ} \mathrm{C}$, cells were fixed with methanol and stained with crystal violet for $30 \mathrm{~min}$ at room temperature. Noninvaded cells on the top of the Transwell were scraped off with a cotton swab. The number of cells in five randomly selected fields of view were imaged under a photomicroscope (light) and counted using Image-Pro Plus 6.0 (Media Cybernetic, Inc.).

Western blotting. A2780 cells overexpressing miR-let-7b or control miRNA were lysed in RIPA buffer $(25.0 \mathrm{mM}$ Tris- $\mathrm{HCl}$, pH 7.6, $150.0 \mathrm{mM} \mathrm{NaCl}, 1.0 \mathrm{NP}-40,1.0$ sodium deoxycholate and $0.1 \%$ SDS) containing protease and phosphatase inhibitors. Protein quantification was performed by BCA Protein Assay (Pierce; Thermo Fisher Scientific, Inc.). Then $20 \mu \mathrm{g}$ of soluble protein were loaded onto each lane of $10 \%$ Bis-Tris gel. The proteins were transferred to polyvinylidene fluoride (PVDF) membrane. For the immunoblot, the membranes were blocked with 5\% skimmed milk (Bio-Rad Laboratories, Inc.) in TBST ( $0.5 \%$ Tween) for $1 \mathrm{~h}$, at room temperature. Primary antibodies (1:1,000 dilution) in 5\% bovine serum albumin (BSA) were added and incubated overnight in $4^{\circ} \mathrm{C}$ on a shaker. The membranes then were washed with TBST and incubated with secondary antibody (1:5,000 dilution) in 5\% skimmed milk at room temperature for $1 \mathrm{~h}$. The membranes then were washed with TBST and incubated with ECL mix (Epizyme; cat. no. SQ202). The membrane was removed from the ECL mix and placed between layers of plastic. The membrane was then exposed to autoradiography film (Kodak) using an OPTIMAX X-Ray Film Processor (Protec $\mathrm{GmbH}$ ) in a dark room. Rabbit antibody against COL3A1 (cat. no. 22734), mouse antibody against GAPDH (cat. no. 60004) and horseradish peroxidase-conjugated secondary antibodies (cat. no. SA00001-1 and SA00001-2) were obtained from ProteinTech Group, Inc.

Flow cytometry assay. Apoptotic rate was detected by flow cytometry using an Annexin V apoptosis detection kit (Invitrogen; Thermo Fisher Scientific, Inc.), according to the manufacturer's protocol. A2780 cells overexpressing miR-let-7b or control miRNA were treated with Taxol $(0$, $6.25,12.5,25,50,100 \mathrm{nM}$ ) for $16 \mathrm{~h}$, then were collected for detection. A2780, A2780/TR, SK-OV-3 and SK-OV-3/TR cells were pre-treated with $25 \mu \mathrm{g} / \mathrm{ml}$ of RRTS for $24 \mathrm{~h}$, followed by $25 \mathrm{nM}$ of Taxol for a further $24 \mathrm{~h}$, then were collected for detection.

In this flow cytometry assay, A2780, A2780/TR, SK-OV-3 and SK-OV-3/TR cells were rinsed with ice-cold PBS, followed by rinsing with binding buffer and adjusted to $1 \times 10^{5}$ cells $/ \mathrm{ml}$. Next, $100 \mu 1$ of cell suspension was stained with $5 \mu 1$ of Annexin V-APC for $15 \mathrm{~min}$ in the dark at room temperature. Following another rinse with binding buffer, $5 \mu 1$ of PI was added to the cells and incubated on ice for $5 \mathrm{~min}$. Following filtration, the cell mixture was analyzed using FASCcan Flow Cytometer (BD Biosciences) and data were analyzed using FlowJo_V10 (FlowJo LLC).

Isobolographic analysis. Isobolographic analysis was performed to characterize the extent of the interaction between RRTS and Taxol in A2780 cells. The $\mathrm{IC}_{50}$ (half maximal inhibitory concentration) of Taxol $(32.5 \mathrm{nM})$ and RRTS $(42 \mu \mathrm{g} / \mathrm{ml})$ were plotted on the $\mathrm{x}$ and $\mathrm{y}$ axes in a two-coordinate plot. In order to connect the IC50 value of each drug alone and that of the combination, a nonlinear regression analysis (equation $\mathrm{y}=$ (top-bottom) $\mathrm{x} \exp (-\mathrm{kx})+$ bottom) has been carried out by GraphPad Prism 5 (GraphPad Software, Inc.) $(25,26)$. The line connecting these two points represented an additive interaction. The concentrations of drugs used in combination were placed in the same plot.

The effect was considered synergistic when the plot was located below the line and antagonistic when the plot was above the line.

In vivo ovarian cancer xenograft model. Animal protocols were approved by the animal care committee of Guangdong Provincial People's Hospital (approval no. GDREC2019582A). This study was approved in 2019. A total of 36 mice were used in this study. At the start of the study, the body weight ranged from 18.5-20 g. Throughout the entire project, the mice were 
A

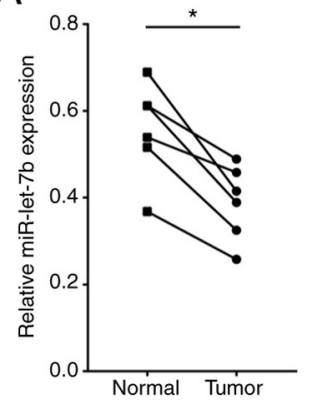

B

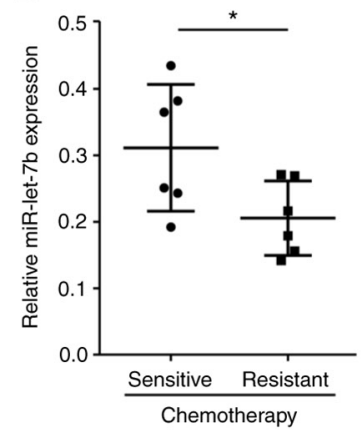

C

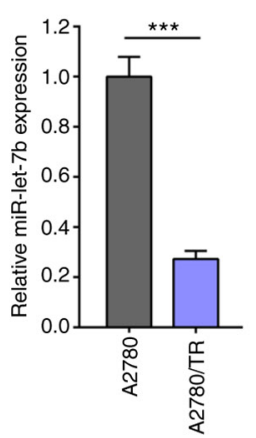

$\mathrm{D}$

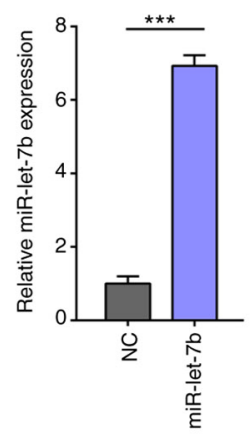

$E$

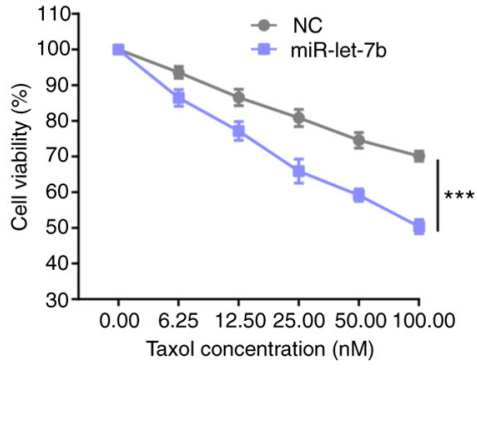

$\mathrm{F}$
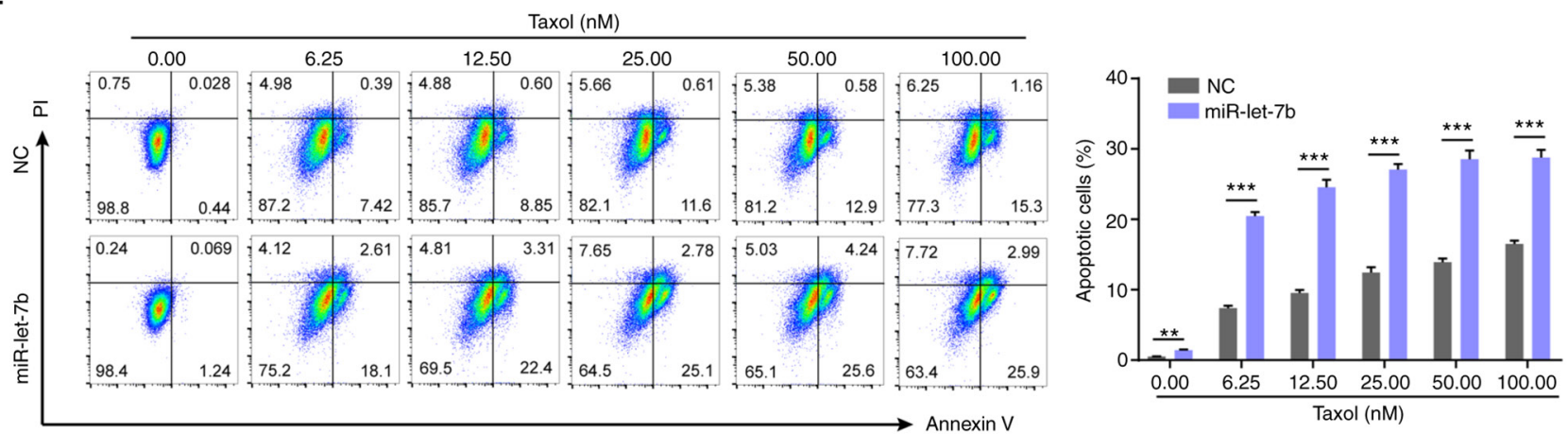

Figure 1. miR-let-7b contributes to Taxol resistance in ovarian cancer. (A) Levels of miR-let-7b in six pairs of ovarian cancer and matched normal fallopian tube tissue. (B) miR-let-7b expression was decreased significantly in chemoresistant ovarian cancer patients. (C) miR-let-7b expression was decreased significantly in A2780/TR cells. (D) Reverse transcription-quantitative PCR confirmed overexpression of miR-let-7b in A2780 cells. (E) miR-let-7b overexpression increased the sensitivity of A2780 cells to Taxol. A2780 cells transfected with either miR-let-7b or control miRNA were treated with Taxol and cell viability was assessed via Cell Counting Kit-8 assay. (F) A2780 cells transfected with miR-let-7b or control miRNA were treated with Taxol for 48 h. Cell apoptosis was assessed by flow cytometry using Annexin V-PI dual-staining assay. ${ }^{*} \mathrm{P}<0.05,{ }^{* *} \mathrm{P}<0.01$ and ${ }^{* * * *} \mathrm{P}<0.001$. miR, microRNA; let, lethal; NC, negative control; TR, Taxol-resistant.

housed in standard polypropylene cages, at optimum density and in standard laboratory conditions (temperature $25 \pm 1^{\circ} \mathrm{C}$ relative humidity $55 \pm 5 \%$, and $12 \mathrm{~h}$ light/dark cycle). They were allowed free access to standard granular diet and water. A2780 cells $\left(1 \times 10^{6}\right)$ were injected subcutaneously into the back of six-week-old BALB/c nu/nu female mice. At 3 weeks post-inoculation, tumor formation was observed and nude mice were randomly divided into 4 groups $(\mathrm{n}=9)$ as follows: Control (saline); RRTS $(25 \mathrm{mg} / \mathrm{kg})$; Taxol $(15 \mathrm{mg} / \mathrm{kg})$ and $25 \mathrm{mg} / \mathrm{kg}$ RRTS $+15 \mathrm{mg} / \mathrm{kg}$ Taxol. Nude mice were intraperitoneally injected once/week for 6 weeks. Tumor volume was recorded weekly for duration of experiment. Tumor volume was estimated as follows: Volume $=($ longest diameter $\mathrm{x}$ shortest diameter ${ }^{2} / 2$. The mice were euthanized humanely by $\mathrm{CO}_{2}$ asphyxiation at the end of the experiment or when tumor growth was excessive (diameter $\geq 20 \mathrm{~mm}$ ). A displacement rate of $25 \%$ chamber volume/min was used for euthanasia.

Statistical analysis. SPSS 16.0 (SPSS, Inc.) and GraphPad Prism 5 (GraphPad Software, Inc.) were used for statistical analysis. Paired t-test was used to compare ovarian cancer and adjacent healthy tissue. An unpaired t-test was utilized to analyze data conforming to normal distribution and homogeneity of variance between two groups. The association between miR-let-7b and COL3A1 expression in tumor tissues was analyzed using Spearman's correlation analysis. All experiments were repeated three times unless stated otherwise.
Data are presented as the mean $\pm \mathrm{SD}$. Two-sided $\mathrm{P}<0.05$ was considered to indicate a statistically significant difference.

\section{Results}

miR-let-7b modulates sensitivity of ovarian cancer to Taxol. In the present study, miR-let-7b was detected in six pairs of primary ovarian cancer and corresponding healthy tissue. miR-let-7b was downregulated in tumors (Fig. 1A). Further comparison between 12 chemo-sensitive and -resistant ovarian cancer tissue found that miR-let-7b expression levels were lower in patients with chemoresistance (Fig. 1B). miR-let-7b expression was also decreased in A2780/TR cells (Fig. 1C). These results suggested that miR-let-7b downregulation may be involved in Taxol resistance of ovarian cancer. miR-let-7b mimic or control miRNA was transfected into A2780 cells (Fig. 1D) to confirm these results. Following treatment with Taxol, viability and apoptosis of A2780 cells overexpressing miR-let-7b were compared with control miRNA-transfected cells. Cell viability decreased and apoptosis increased in a dose-dependent manner when cells were exposed to Taxol. Cells with miR-let-7b overexpression were more sensitive to Taxol. Following treatment with $100 \mathrm{nM}$ Taxol for $24 \mathrm{~h}$, the viability of control miRNA-transfected A2780 cells was decreased to $70.1 \%$, while that of miR-let-7b overexpressing A2780 cells was decreased to $50.4 \%$ (Fig. 1E). Meanwhile, apoptosis rate was increased to $16.46 \%$ in control 

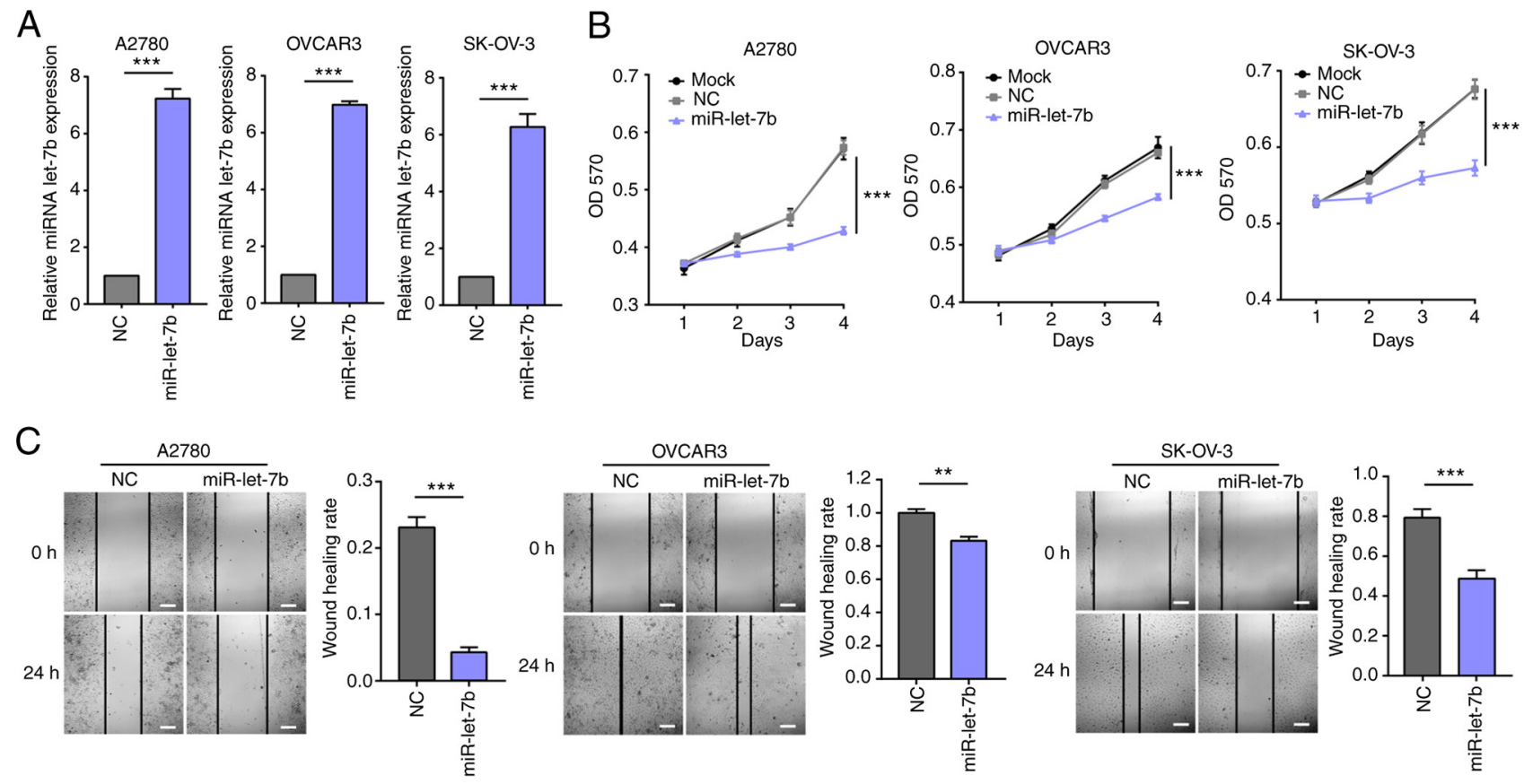

$\mathrm{D}$
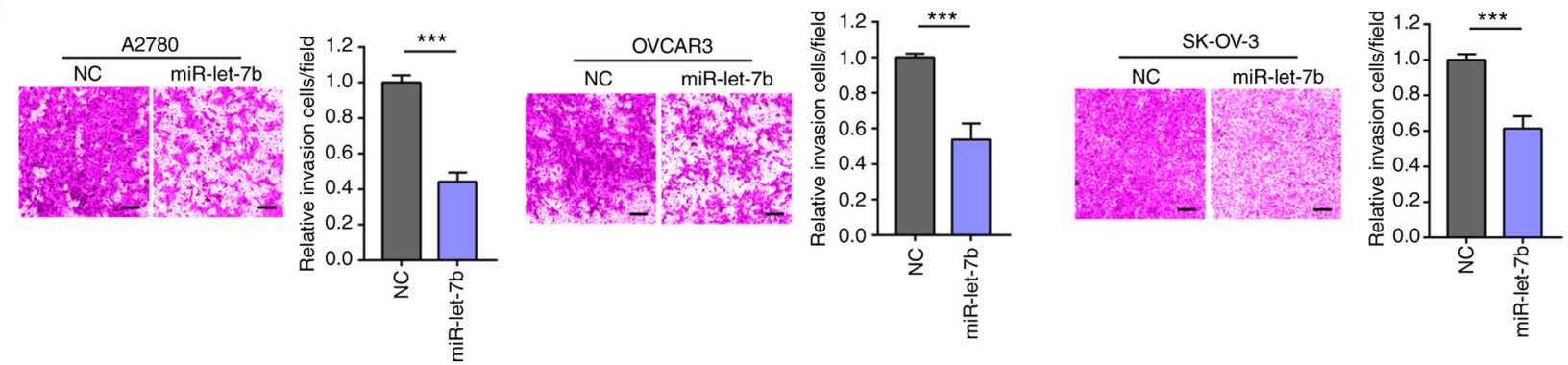

Figure 2. miR-let-7b regulates proliferation, colony formation, migration and invasion of ovarian cancer cells. (A) RT-qPCR assay verified overexpression of miR-let-7b in A2780, OVCAR3 and SK-OV-3 cells. (B) Viability of A2780, OVCAR3 and SK-OV-3 cells transfected with either miR-let-7b or control miRNA was evaluated by MTT assay. (C) Migration ability of A2780, OVCAR3 and SK-OV-3 cells transfected with miR-let-7b or control miRNA was evaluated by wound healing assay. Would healing rate=(initial SA-final SA)/initial SA. Scale bar, $100 \mu \mathrm{m}$. (D) Invaded ability of A2780, OVCAR3 and SK-OV-3 cells transfected with either miR-let-7b or control miRNA was evaluated by Matrigel assay. Scale bar, $100 \mu \mathrm{m} .{ }^{* * *} \mathrm{P}<0.01$ and ${ }^{* * * *} \mathrm{P}<0.001$. miR, microRNA; let, lethal; OD, optical density; SA, scratch area.

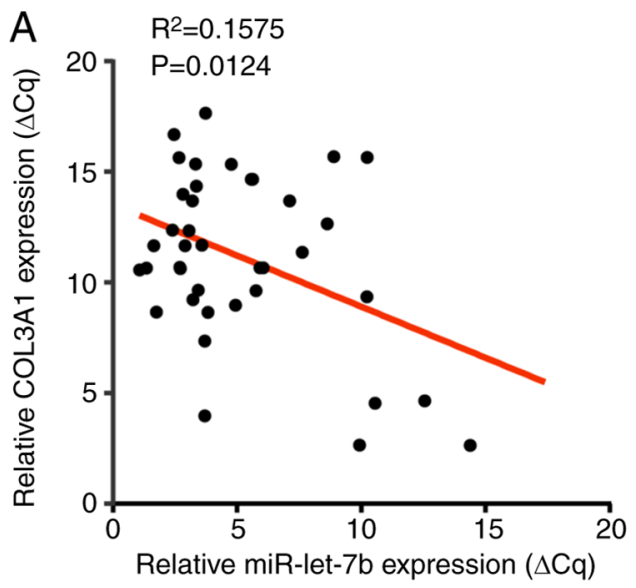

B
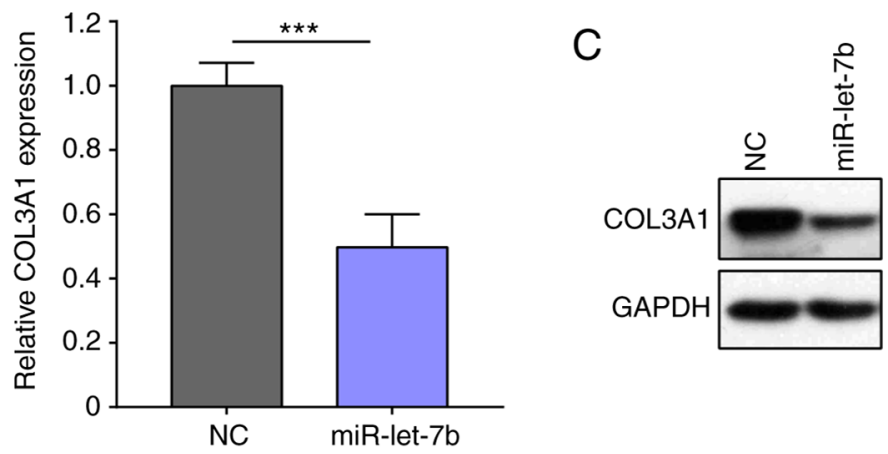

Figure 3. miR-let-7b is inversely correlated with COL3A1 expression in ovarian cancer. (A) Inverse correlation between miR-let-7b and COL3A1 expression in ovarian cancer tissue was determined using Spearman's correlation analysis $(\mathrm{n}=39)$. (B) mRNA and (C) protein expression levels of COL3A1 were decreased in miR-let-7b-overexpressing A2780 cells. ${ }^{* * *} \mathrm{P}<0.001$. COL3A1, collagen type II $\alpha 1$ chain; miR, microRNA; let, lethal; NC, negative control.

miRNA-transfected A2780 cells and $28.89 \%$ in miR-let-7b overexpressing A2780 cells (Fig. 1F). These results indicated that upregulated miR-let-7b expression sensitized ovarian cancer cells to Taxol. 

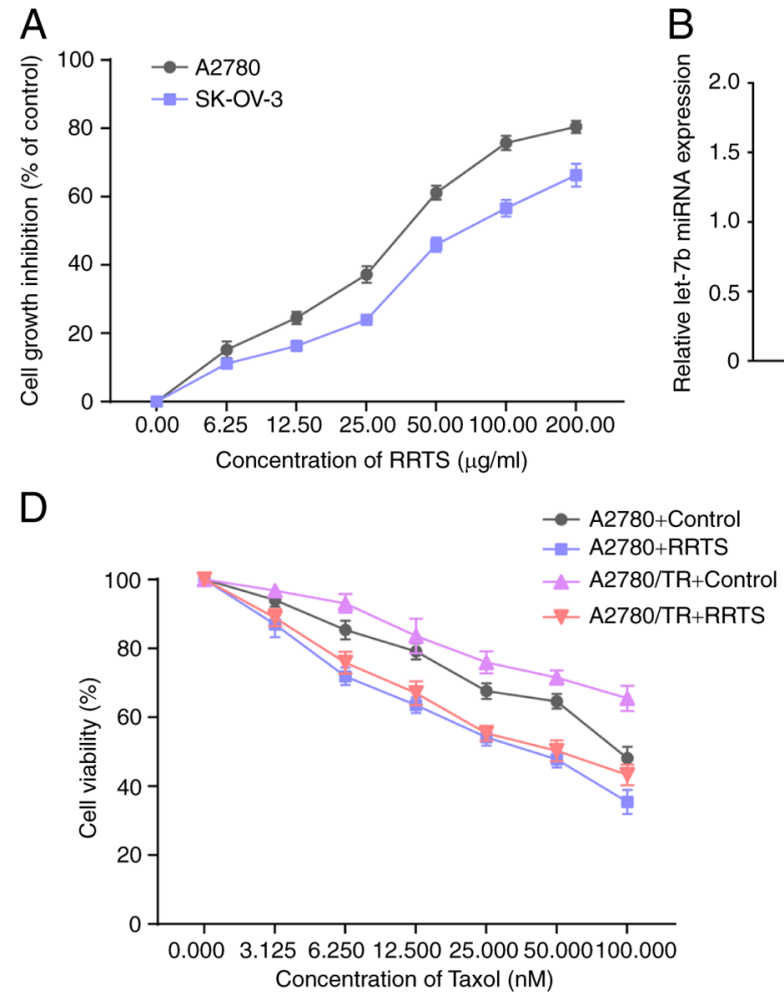

$\mathrm{F}$
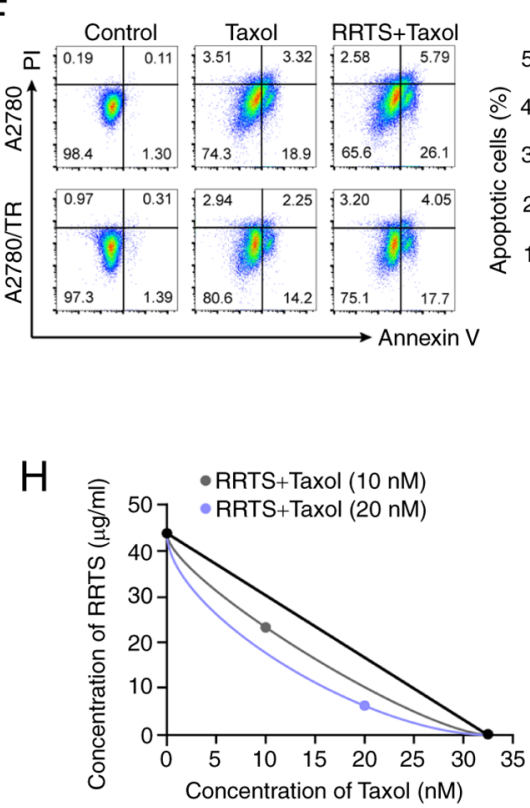

I
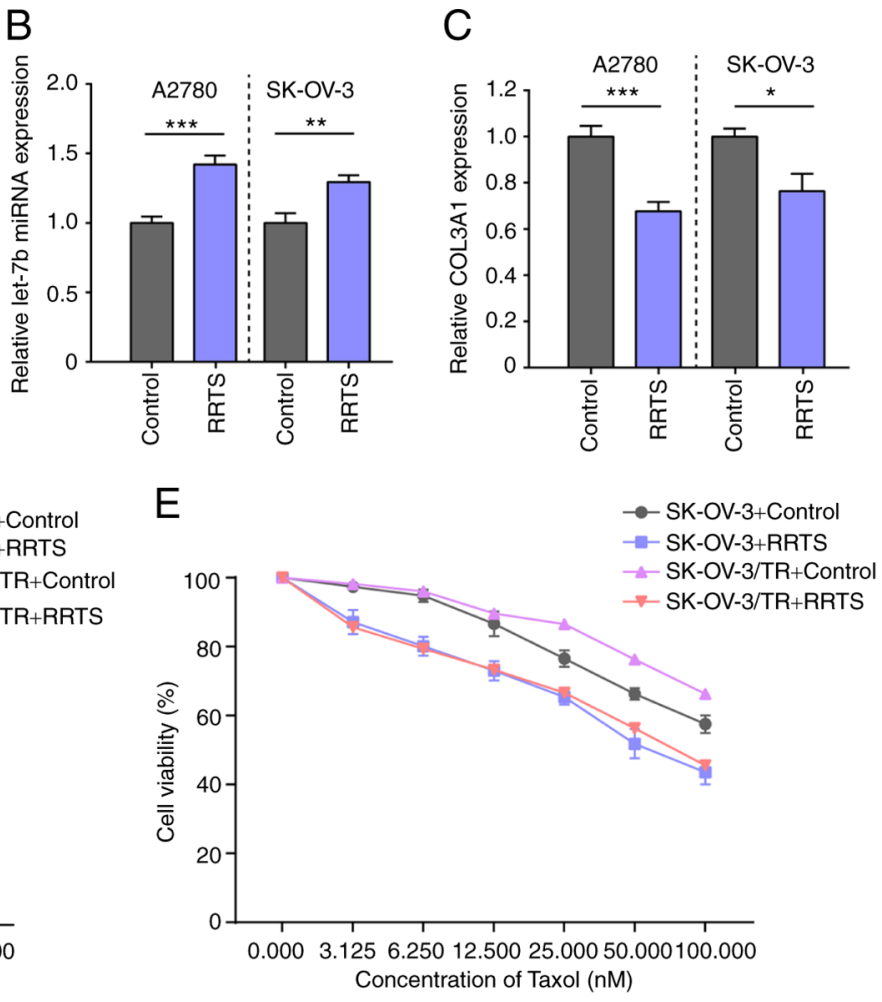

G
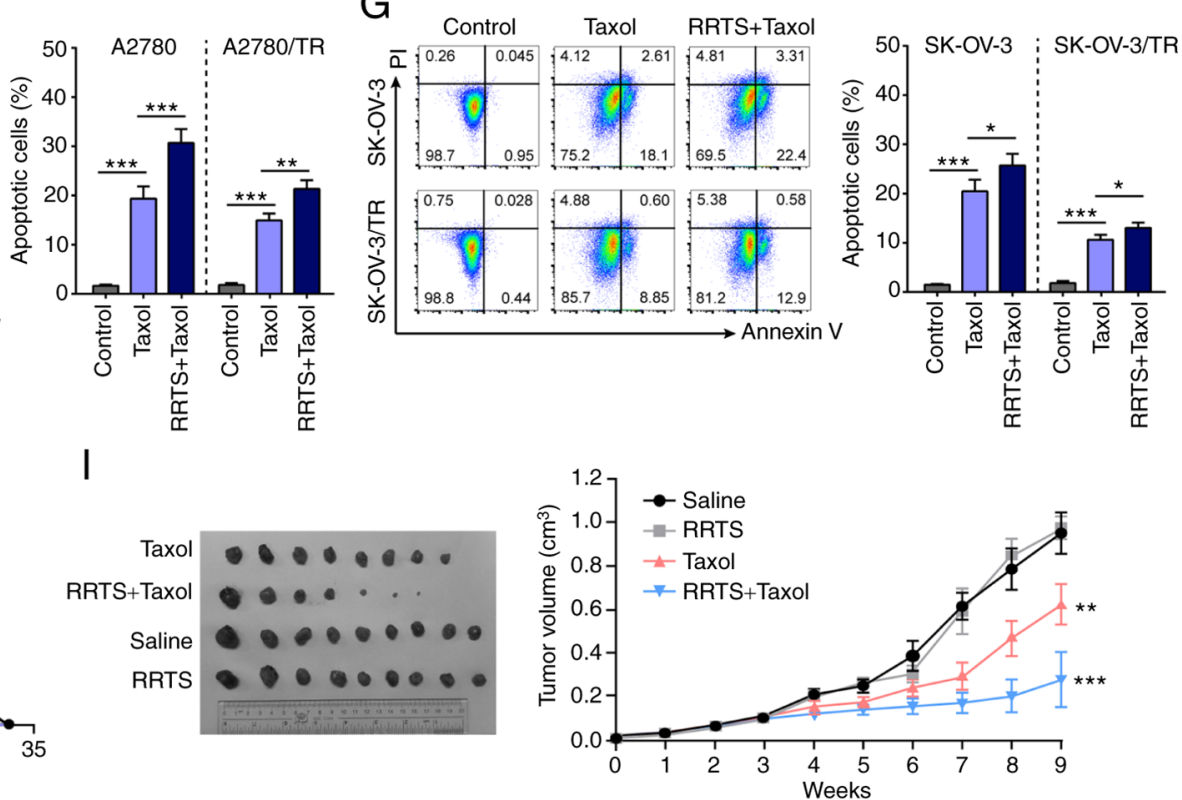

Figure 4. RRTS treatment sensitizes ovarian cancer to Taxol. (A) RRTS exerted an inhibitory effect on proliferation of A2780 and SK-OV-3 cells. A2780 and SK-OV-3 cells were treated with RRTS $(0.00,6.25,12.50,25.00,50.00,100.00$ and $200.00 \mu \mathrm{g} / \mathrm{ml})$ for $24 \mathrm{~h}$. Cell viability was evaluated by Cell Counting Kit- 8 assay. (B) RRTS treatment induced miR-let-7b expression in A2780 and SK-OV-3 cells. (C) RRTS treatment decreased COL3A1 expression in A2780 and SK-OV-3 cells. RRTS $(25 \mu \mathrm{g} / \mathrm{ml})$ pre-treatment increased the sensitivity of (D) SK-OV-3 and (E) SK-OV-3/TR cells to Taxol. RRTS (25 $\mu \mathrm{g} / \mathrm{ml})$ pre-treatment increased apoptosis of Taxol-treated (25 nM) (F) A2780 and A2780/TR and (G) SK-OV-3 and SK-OV-3/TR cells. Cell apoptosis was assessed by flow cytometry using Annexin V-PI dual-staining. (H) Isobolographic analysis of the cytotoxic effect obtained with the combination of RRTS and Taxol at the concentrations of 10 and $20 \mathrm{nM}$ in A2780 cells. The same level of apoptosis can be induced by $32.5 \mathrm{nM}$ Taxol and $42 \mu \mathrm{g} / \mathrm{ml}$ RRTS. (I) A2780 cells were injected into nude mice. RRTS, Taxol or saline was intraperitoneally injected once/week for 6 weeks. Tumors were measured with Vernier Calipers. "P<0.05, ${ }^{* *} \mathrm{P}<0.01,{ }^{* * *} \mathrm{P}<0.001$. COL3A1, collagen type II $\alpha 1$ chain; miR, microRNA; let, lethal; NC, negative control; RRTS, Radix ranunculus temate saponins; TR, Taxol-resistant.

miR-let-7b suppresses the aggressiveness of ovarian cancer cells. To assess the biological role of miR-let-7b in ovarian cancer, the proliferation ability of ovarian cancers cells overexpressing miR-let-7b or control miRNA was determined (Fig. 2A). Overexpression of miR-let-7b significantly decreased the proliferation (Fig. 2B) of A2780, OVCAR3 and SK-OV-3 cells, which indicated an anti-tumor effect of miR-let-7b in ovarian cancer. Subsequently, the effect of miR-let-7b expression on migration and invasion of ovarian cancer cells was assessed in vitro. miR-let-7b overexpression 
significantly suppressed migration and invasion of ovarian cancer cells (Fig. 2C and D). These results demonstrated the role of miR-let-7b in blocking progression of ovarian cancer in vitro.

miR-let-7b supresses expression of COL3A1 in ovarian cancer. To test whether the regulating effect miR-let-7b on COL3A1 is conserved in vivo, the present study analyzed the association between expression of miR-let-7b and COL3A1 in samples from 39 patients with primary ovarian cancer. COL3A1 expression was inversely associated with miR-let-7b expression (Fig. 3A). Ovarian cancer cell line was used to confirm that miR-let-7b overexpression downregulated COL3A1 expression (Fig. 3B and C).

RRTS sensitizes ovarian cancer cells to Taxol treatment. The present study evaluated the cytotoxic effect of RRTS on A2780 and SK-OV-3 cells. RRTS displayed a notable cytotoxic effect on both cell lines; the inhibitory effect on cell proliferation was dose-dependent, with an inhibition rate of $82.6 \%\left(\mathrm{IC}_{50}=37.22 \pm 3.54 \mu \mathrm{g} / \mathrm{ml}\right)$ in $\mathrm{A} 2780$ and $64.8 \%$ at $200 \mu \mathrm{g} / \mathrm{ml}\left(\mathrm{IC}_{50}=45.58 \pm 4.76 \mu \mathrm{g} / \mathrm{ml}\right)$ in SK-OV-3 cells (Fig. 4A). These data suggested that RRTS killed tumor cells effectively. RRTS treatment induced miR-let-7b expression in A2780 and SK-OV-3 cells (Fig. 4B) and decreased COL3A1 expression (Fig. 4C). Subsequently, it was investigated whether RRTS sensitizes ovarian cancer cells to Taxol. A2780, A2780/TR, SK-OV-3 and SK-OV-3/TR cells were pre-treated with $25 \mu \mathrm{g} / \mathrm{ml}$ RRTS for $24 \mathrm{~h}$, followed by Taxol $(0.000,3.125$, $6.250,12.50,25.000,50.000$ and $100.000 \mathrm{nM}$ ) for a further $24 \mathrm{~h}$. Cell viability was decreased following sequential treatment (Fig. 4D and E). In addition, cell apoptosis was increased following sequential treatment with $25 \mu \mathrm{g} / \mathrm{ml}$ RRTS and $25 \mathrm{nM}$ Taxol (Fig. 4F and G). To determine the interaction between RRTS and Taxol, a detailed isobolographic analysis was performed. The combined treatment showed synergistic effect in A2780 cells (Fig. 4H). The effect of combined treatment was also assessed in vivo. A2780 cells were subcutaneously injected into BALB/c nude mice. The mice were randomly assigned into saline, RRTS, Taxol or combined treatment groups when they developed palpable tumors $(>5 \mathrm{~mm}$ diameter; 3 weeks). RRTS ( $25 \mathrm{mg} / \mathrm{kg})$, Taxol $(15 \mathrm{mg} / \mathrm{kg}$ ) or an equal volume of saline were intraperitoneally injected once/week for 6 weeks. Taxol inhibited tumor growth. Although RRTS treatment showed no notable inhibitory effect, the combination of RRTS and Taxol induced a synergistic significant decrease in tumor growth (Fig. 4I). These data indicated that RRTS + Taxol synergistically killed ovarian cancer cells.

\section{Discussion}

Ovarian cancer is the leading cause of mortality in gynecological malignancy (27). The front-line treatment for ovarian cancer is primarily surgery, supplemented by chemotherapy (28). Certain patients are treated with targeted therapy (28). However, eventual tumor recurrence and development of chemotherapy resistance shorten the long-term survival of patients. Paclitaxel is one of the most widely used chemotherapeutic agents in cancer treatment and acts by blocking the cell cycle and inducing cell apoptosis (29). Taxol resistance occurs during treatment and limits the therapeutic effect, thus negatively affecting the prognosis of patients with advanced ovarian cancer (30). Therefore, it is essential to decrease chemoresistance in these patients. The mechanism of Taxol resistance has been described before (31). Tumor-specific cell cycle deregulation and alterations to tubulin structure are associated with Taxol resistance (31). Taxol is a substrate for $\mathrm{ABC}$ transporter, which functions as a drug-efflux pump; overexpression of this transport system in breast cancer is associated with resistance to Taxol (32). However, only a small percentage of ovarian cancers show high level of ABCB1 expression after Taxok treatment (33), the underlying mechanism for the development of Taxol resistance in ovarian cancer remain to be elucidated.

miRNAs are small non-coding RNAs that regulate the expression of target genes, which take participate physiological and pathological processes. Due to the specific expression patterns that are associated with prognosis, miRNAs are potential tumor markers $(34,35)$. For example, high expression of miR-221 and miR-let-7 is associated with good prognosis, as opposed to elevated miR-137, miR-372 and miR-182, which is associated with poor prognosis in patients with lung cancer (36). Plasma miR-10b and miR-373 are potential prognostic biomarkers for breast cancer (37). Additionally, expression levels of miR-410 and miR-645 are negatively associated with overall survival in advanced serous ovarian cancer (38). The let-7 miRNA family is considered to be a tumor suppressor gene based on its effects on decreasing cancer aggressiveness, chemoresistance and radioresistance (39). In multiple types of human cancer, such as multiple myeloma, glioma and osteosarcoma, miR-let-7b expression is downregulated and associated with tumor progression (16-18). The present study found that miR-let-7b expression was significantly downregulated in ovarian cancer tissue, particularly in patients with chemoresistance. Additionally, overexpression of miR-let-7b increased the sensitivity of ovarian cancer cell lines to Taxol.

Collagen is a primary component of the tumor microenvironment that favors tumor progression (40). In solid tumors, increased collagen content is associated with chemotherapy resistance via integrins, discoidin domain and tyrosine kinase receptors and other signaling pathways (40). Collagen serves as a barrier to limit diffusion of therapeutic agents into tumor tissue $(41,42)$. The diffusion speed of molecules is inversely associated with levels of fibrillar collagen in extracellular matrix $(43,44)$. Certain cytostatic drugs, such as methotrexate, vinblastine and paclitaxel, bind to collagen, limiting their availability to tumor tissue (42). Knowledge of collagen regulation may provide options for overcoming chemoresistance.

Multiple types of collagen are highly expressed in ovarian cancer $(45,46)$. COL $3 \mathrm{~A} 1$ is the most abundantly expressed collagen in ovarian cancer cell lines (46). High expression of COL3A1 is observed in paclitaxel-, topotecan- and cisplatin-resistant cell lines, suggesting that COL3A1 is associated with resistance of ovarian cancer to chemotherapy (46). Previous studies also confirmed that COL3A1 is associated with shortened overall survival of patients with ovarian carcinoma $(47,48)$. Collagen biosynthesis is regulated by tumor cells via numerous signaling pathways, including mutated 
genes, transcription factors, signaling pathways and receptors (40). miRNAs are associated with collagen in cancer. Several collagens, such as COL1A1, COL1A2 and COL3A1, are targets of miR-let-7b (49-51). The present results were consistent with a previous study (49): COL3A1 mRNA was inversely correlated with miR-let-7b levels in ovarian cancer clinical specimens. Overexpression of miR-let-7b downregulated COL $3 \mathrm{~A} 1$ in ovarian cancer cell lines. These results partially identified the role of miR-let-7b in chemotherapy resistance of patients with ovarian cancer. The present findings also suggested that the miR-let-7b/COL3A1 regulatory pathway served a role in ovarian cancer aggressiveness and chemotherapy resistance.

Radix Ranunculus ternati, a traditional Chinese herbal medicine, has been used to treat numerous types of disease and as an adjuvant therapy for cancer many years (19). The pharmacology of Radix $R$. ternate depend on saponins and polysaccharides $(20,21)$. However, further evidence is needed to prove their anti-tumor effect. The present study demonstrated that RRTS induced miR-let-7b expression to suppress the aggressiveness of tumor cells. No notable side effects of RRTS $(25 \mathrm{mg} / \mathrm{kg}$ ) were observed in animal experiments. Although RRTS exhibited no notable effect on tumor growth, it enhanced the inhibitory effect of Taxol. The present study aimed to evaluate the theraputic effect of RRTS on human ovarian cancer cells with Taxol resistance and demonstrated that RRTS may be a novel adjuvant for Taxol chemotherapy.

\section{Acknowledgements}

Not applicable.

\section{Funding}

The present study was supported by Scientific Research Projects of Guangdong Traditional Chinese Medicine Bureau (grant nos. 20191011 and 20201002) and the Project of Guangzhou Science and Technology Plan (grant nos. 201904010031 and 202102080046).

\section{Availability of data and materials}

The datasets used and/or analyzed during the current study are available from the corresponding author on reasonable request.

\section{Authors' contributions}

WL, KY and HY conceived and designed the experiments, revised the manuscript and confirm the authenticity of all the raw data. WL, KY, YL and LC performed the experiments. WL analyzed and interpreted the data and wrote the manuscript. All the authors have read and approved the final manuscript.

\section{Ethics approval and consent to participate}

Written informed consent was obtained from all patients. The study protocol was approved by the Ethics Committee of Guangdong Provincial People's Hospital [approval nos. GDREC2019582A and GDREC2019582H(R1)].

\section{Patient consent for publication}

Not applicable.

\section{Competing interests}

The authors declare that they have no competing interests.

\section{References}

1. Matulonis UA, Sood AK, Fallowfield L, Howitt BE, Sehouli J and Karlan BY: Ovarian cancer. Nat Rev Dis Primers 2: 16061, 2016.

2. Lheureux S, Gourley C, Vergote I and Oza AM: Epithelial ovarian cancer. Lancet 393: 1240-1253, 2019.

3. Gorodnova TV, Sokolenko AP, Kuligina E, Berlev IV and Imyanitov EN: Principles of clinical management of ovarian cancer. Chin Clin Oncol 7: 56, 2018.

4. Lee JM, Minasian L and Kohn EC: New strategies in ovarian cancer treatment. Cancer 125 (Suppl 24): S4623-S4629, 2019

5. Christie EL and Bowtell DDL: Acquired chemotherapy resistance in ovarian cancer. Ann Oncol 28 (Suppl 8): viii13-viii15, 2017.

6. Freimund AE, Beach JA, Christie EL and Bowtell DDL: Mechanisms of drug resistance in high-grade serous ovarian cancer. Hematol Oncol Clin North Am 32: 983-996, 2018.

7. Patch AM, Christie EL, Etemadmoghadam D, Garsed DW, George J, Fereday S, Nones K, Cowin P, Alsop K, Bailey P, et al: Whole-genome characterization of chemoresistant ovarian cancer. Nature 521: 489-494, 2015.

8. Gebert LFR and MacRae IJ: Regulation of microRNA function in animals. Nat Rev Mol Cell Biol 20: 21-37, 2019.

9. Dragomir MP, Knutsen E and Calin GA: Classical and noncanonical functions of miRNAs in cancers. Trends Genet: Oct 30, 2021 (Epub ahead of print).

10. Rupaimoole R and Slack FJ: MicroRNA therapeutics: Towards a new era for the management of cancer and other diseases. Nat Rev Drug Discov 16: 203-222, 2017.

11. Goodall GJ and Wickramasinghe VO: RNA in cancer. Nat Rev Cancer 21: 22-36, 2021.

12. Peng $\mathrm{Y}$ and Croce $\mathrm{CM}$ : The role of MicroRNAs in human cancer. Signal Transduct Target Ther 1: 15004, 2016.

13. Ayers D and Vandesompele J: Influence of microRNAs and Long Non-Coding RNAs in Cancer Chemoresistance. Genes (Basel) 8: 95, 2017.

14. Fu TY, Chang CC, Lin CT, Lai CH, Peng SY, Ko YJ and Tang PC: Let-7b-mediated suppression of basigin expression and metastasis in mouse melanoma cells. Exp Cell Res 317: 445-451, 2011.

15. Zhao Y, Deng C, Lu W, Xiao J, Ma D, Guo M, Recker RR, Gatalica Z, Wang Z and Xiao GG: Let-7 microRNAs induce tamoxifen sensitivity by downregulation of estrogen receptor alpha signaling in breast cancer. Mol Med 17: 1233-1241, 2011.

16. Xu H, Liu C, Zhang Y, Guo X, Liu Z, Luo Z, Chang Y, Liu S, Sun $Z$ and Wang $X$ : Let-7b-5p regulates proliferation and apoptosis in multiple myeloma by targeting IGF1R. Acta Biochim Biophys Sin (Shanghai) 46: 965-972, 2014.

17. Zhang W, Zhao W, Ge C, Li X, Yang X, Xiang Y and Sun Z: Decreased let-7b is associated with poor prognosis in glioma. Medicine (Baltimore) 98: e15784, 2019.

18. Chen F, Chen C, Yang S, Gong W, Wang Y, Cianflone K, Tang J and Wang DW: Let-7b inhibits human cancer phenotype by targeting cytochrome P450 epoxygenase 2J2. PLoS One 7: e39197, 2012.

19. China Pharmacopoeia Committee: Pharmacopoeia of the People's Republic of China. China Chemical Industry Press, Beijing, pp223-224, 2005.

20. Tian JK, Sun F and Cheng YY: Chemical constituents from the roots of Ranunculus ternatus. J Asian Nat Prod Res 8: 35-39, 2006.

21. Deng KZ, Xiong Y, Zhou B, Guan YM and Luo YM: Chemical constituents from the roots of Ranunculus ternatus and their inhibitory effects on Mycobacterium tuberculosis. Molecules 18: 11859-11865, 2013.

22. Li ML, Gu HM, Hang HY, Jiang YL, Jiang J, Gu QN and WU WY: Radix ranunculus temate saponins induces apoptosis via the death receptor and mitochondrial pathways in SGC-7901 cells. Mol Cell Toxicol 11: 449-455, 2015. 
23. Niu L, Zhou Y, Sun B, Hu J, Kong L and Duan S: Inhibitory effect of saponins and polysaccharides from Radix ranunculi ternati on human gastric cancer BGC823 cells. Afr J Tradit Complement Altern Med 10: 561-566, 2013.

24. Livak KJ and Schmittgen TD: Analysis of relative gene expression data using real-time quantitative PCR and the 2(-Delta Delta C(T)) Method. Methods 25: 402-408, 2001.

25. Di Sotto A, Irannejad H, Eufemi M, Mancinelli R, Abete L, Mammola CL, Altieri F, Mazzanti G and Di Giacomo S: Potentiation of Low-Dose Doxorubicin Cytotoxicity by Affecting P-Glycoprotein through Caryophyllane Sesquiterpenes in HepG2 Cells: An in vitro and in silico study. Int J Mol Sci 21: 633, 2020.

26. DI Giacomo S, DI Sotto A, Mazzanti G and Wink M: Chemosensitizing properties of $\beta$-caryophyllene and $\beta$-caryophyllene oxide in combination with doxorubicin in human cancer cells. Anticancer Res 37: 1191-1196, 2017.

27. Redondo A, Guerra E, Manso L, Martin-Lorente C, Martinez-Garcia J, Perez-Fidalgo JA, Varela MQ, Rubio MJ Barretina-Ginesta MP and Gonzalez-Martin A: SEOM clinical guideline in ovarian cancer (2020). Clin Transl Oncol 23: 961-968, 2021.

28. Marth C, Reimer D and Zeimet AG: Front-line therapy of advanced epithelial ovarian cancer: Standard treatment. Ann Oncol 28 (Suppl 8): viii36-viii39, 2017.

29. Weaver BA: How Taxol/paclitaxel kills cancer cells. Mol Biol Cell 25: 2677-2681, 2014.

30. Pokhriyal R, Hariprasad R, Kumar L and Hariprasad G: Chemotherapy resistance in advanced ovarian cancer patients. Biomark Cancer 11: 1179299X19860815, 2019.

31. Kavallaris M: Microtubules and resistance to tubulin-binding agents. Nat Rev Cancer 10: 194-204, 2010.

32. Robey RW, Pluchino KM, Hall MD, Fojo AT, Bates SE and Gottesman MM: Revisiting the role of ABC transporters in multidrug-resistant cancer. Nat Rev Cancer 18: 452-464, 2018.

33. Gillet JP, Wang J, Calcagno AM, Green LJ, Varma S, Bunkholt Elstrand M, Trope CG, Ambudkar SV, Davidson B and Gottesman MM: Clinical relevance of multidrug resistance gene expression in ovarian serous carcinoma effusions. Mol Pharm 8: 2080-2088, 2011.

34. Hayes J, Peruzzi PP and Lawler S: MicroRNAs in cancer: Biomarkers, functions and therapy. Trends Mol Med 20: 460-469, 2014.

35. Lan $\mathrm{H}$, Lu H, Wang $\mathrm{X}$ and Jin H: MicroRNAs as potential biomarkers in cancer: Opportunities and challenges. Biomed Res Int 2015: 125094, 2015.

36. Markou A, Liang Y and Lianidou E: Prognostic, therapeutic and diagnostic potential of microRNAs in non-small cell lung cancer. Clin Chem Lab Med 49: 1591-1603, 2011.

37. Chen W, Cai F, Zhang B, Barekati Z and Zhong XY: The level of circulating miRNA-10b and miRNA-373 in detecting lymph node metastasis of breast cancer: Potential biomarkers. Tumour Biol 34: 455-462, 2013.

38. Shih KK, Qin LX, Tanner EJ, Zhou Q, Bisogna M, Dao F, Olvera N, Viale A, Barakat RR and Levine DA: A microRNA survival signature (MiSS) for advanced ovarian cancer. Gynecol Oncol 121: 444-450, 2011.
39. Chirshev E, Oberg KC, Ioffe YJ and Unternaehrer JJ: Let-7 as biomarker, prognostic indicator, and therapy for precision medicine in cancer. Clin Trans Med 8: 24, 2019.

40. Xu S, Xu H, Wang W, Li S, Li H, Li T, Zhang W, Yu X and Liu L: The role of collagen in cancer: From bench to bedside. J Transl Med 17: 309, 2019.

41. Chauhan VP, Stylianopoulos T, Boucher Y and Jain RK: Delivery of molecular and nanoscale medicine to tumors: Transport barriers and strategies. Annu Rev Chem Biomol Eng 2: 281-298, 2011.

42. Di Paolo A and Bocci G: Drug distribution in tumors: Mechanisms, role in drug resistance, and methods for modification. Curr Oncol Rep 9: 109-114, 2007.

43. Ramanujan S, Pluen A, McKee TD, Brown EB, Boucher Y and Jain RK: Diffusion and convection in collagen gels: Implications for transport in the tumor interstitiumv. Biophys J 83: 1650-1660, 2002.

44. Brown E, McKee T, diTomaso E, Pluen A, Seed B, Boucher Y and Jain RK: Dynamic imaging of collagen and its modulation in tumors in vivo using second-harmonic generation. Nat Med 9: 796-800, 2003

45. Cho A, Howell VM and Colvin EK: The extracellular matrix in epithelial ovarian cancer-A piece of a puzzle. Front Oncol 5: 245, 2015.

46. Januchowski R, Swierczewska M, Sterzynska K, Wojtowicz K, Nowicki $M$ and Zabel $M$ : Increased expression of several collagen genes is associated with drug resistance in ovarian cancer cell lines. J Cancer 7: 1295-1310, 2016.

47. Engqvist H, Parris TZ, Kovacs A,Nemes S, Werner Rönnerman E, De Lara S, Biermann J, Sundfeldt K, Karlsson P and Helou K Immunohistochemical validation of COL3A1, GPR158 and PITHD1 as prognostic biomarkers in early-stage ovarian carcinomas. BMC Cancer 19: 928, 2019.

48. Sun Q, Zhao H, Zhang C, Hu T, Wu J, Lin X, Luo D, Wang C, Meng L, Xi L, et al: Gene co-expression network reveals shared modules predictive of stage and grade in serous ovarian cancers. Oncotarget 8: 42983-42996, 2017.

49. Wang Q, She Y, Bi X, Zhao B, Ruan X and Tan Y: Dexmedetomidine protects $\mathrm{PC} 12$ cells from lidocaine-induced cytotoxicity through downregulation of COL3A1 mediated by miR-let-7b. DNA Cell Biol 36: 518-528, 2017.

50. Yu DH, Ruan XL, Huang JY, Liu XP, Ma HL, Chen C, $\mathrm{Hu}$ WD and Li S: Analysis of the interaction network of Hub miRNAs-Hub genes, being involved in idiopathic pulmonary fibers and its emerging role in non-small cell lung cancer. Front Genet 11: 302, 2020

51. Liu J, Luo C, Yin Z, Li P, Wang S, Chen J, He Q and Zhou J: Downregulation of let-7b promotes COL1A1 and COL1A2 expression in dermis and skin fibroblasts during heat wound repair. Mol Med Rep 13: 2683-2688, 2016.

This work is licensed under a Creative Commons Attribution-NonCommercial-NoDerivatives 4.0 International (CC BY-NC-ND 4.0) License. 